Vol. 8, Issue 8, August 2021

DOI: $10.17148 / I A R J S E T .2021 .8843$

\title{
Herbal Botanicals to Combat Covid-19
}

\author{
Pooja Dahiya $^{1}$, Roopsi Kaushik ${ }^{2}$, Yagyavalkya Sharma ${ }^{3}$ \\ ${ }^{1}$ PG -Biotechnology, Deenbandhu Chhotu Ram University of Science and Technology, Murthal, Haryana \\ ${ }^{2}$ PG -Biotechnology, Deenbandhu Chhotu Ram University of Science and Technology, Murthal, Haryana \\ ${ }^{3}$ Junior Scientist cum Training Coordinator, Kalp Laboratories, Mathura, Uttar Pradesh
}

\begin{abstract}
Covid-19 showing common symptoms like cough, difficulty in breathing, abdominal pain, vomiting, diarrhoea and fever has been known as a disease since the late $20^{\text {th }}$ century but still no cure has been developed for it. Temporary treatment includes some therapeutic interventions but no antibiotics show their effectiveness on the disease. Due to this common people and researchers are trying to find the best way to cure or prevent the disease including herbal plant products. These herbal botanicals have anti viral, anti inflammatory, immune stimulatory activities which are helpful in the prevention of covid-19 as they are effective against RNA viruses including SARS$\mathrm{CoV}$, MERS-CoV, influenza and other viral diseases.
\end{abstract}

Keywords-COVID-19, MERS-COV, SARS-COV, Herbal compounds

\section{INTRODUCTION}

Coronavirus, for the treatment there are a lot of chemical drugs like flavipiravir, remdesivir, use of vaccines like covaxin, plasma therapies but for the elders and for those patients who are already suffering from other medical problems like allergies towards the chemical compounds this virus can cause severe infection. Naturally occurring herbal botanicals products and various herbal medicines has been widely used since the ancient times for the treatment of respiratory infections. The herbal medicines are considered as ideal because of their minimal toxicity and lowering down of the effect of SARS-CoV-2 infection by acting as immunity boosters. According to world heath organization statistics, there are only $20 \%$ of coronovirus-19 patients who are unable to care for themselves at home via the consumption of kadha. Herbal botanicals are helpful in reduction of stress, sore throats, respiratory congestion and sinuses as well. They serve as boosting agents as antioxidants, vitamin supplements, antibacterial, antivirals, steroids and alkaloids. They also help in reduction of stress.

\section{REVIEW OF LITERATURE}

2.1 Nugraha, R. V., Ridwansyah, H., Ghozali, M., Khairani, A. F., \& Atik, N. (2020). Traditional herbal medicine candidates as complementary treatments for COVID-19: a review of their mechanisms, pros and cons. Evidence-Based Complementary and Alternative Medicine, 2020.

2.2 Silveira, D., Prieto-Garcia, J. M., Boylan, F., Estrada, O., Fonseca-Bazzo, Y. M., Jamal, C. M., ... \& Heinrich, M. (2020). COVID-19: is there evidence for the use of herbal medicines as adjuvant symptomatic therapy?. Frontiers in Pharmacology, 11, 1479.

2.3 Barati, F., Pouresmaieli, M., Ekrami, E., Asghari, S., Ziarani, F. R., \& Mamoudifard, M. (2020). Potential Drugs and Remedies for the Treatment of COVID-19: a Critical Review. Biological Procedures Online, 22(1), 1-17.

2.4 Srivastava, A. K., Chaurasia, J. P., Khan, R., Dhand, C., \& Verma, S. (2020). Role of medicinal plants of traditional use in recuperating devastating COVID-19 situation. Med Aromat Plants (Los Angeles), 9(359), $2167-0412$.

\section{PREVENTION OF COVID USING HERBAL BOTANICALS}

\subsection{Ocimum tenuiflorum (Holy basil, Tulsi)}

The plant of tulsi having the largest curative properties in the system of ayurveda and siddha. It has proved that tulsi has varying number of properties like against bacteria, diabetes, cancer, The anti virulence properties of tulsi are for 
Vol. 8, Issue 8, August 2021

\section{DOI: $10.17148 /$ IARJSET.2021.8843}

both kind of viruses DNA as well as RNA viruses. It is experimentally proven that Tulsi enhances the percentage of numbers of helper T-Lymphocytes and natural Killer cells the kind of WBCs. Tulsi is used to fight against coronavirus because Tulsi extract inhibits the replication of SARS-CoV with ACE2. It also act as natural immunity booster, reduces fever by ingesting it through tea, kind of stress booster plant, having anti cancer properties, boon to patients of diabetes and heart.

\subsection{Zingiber Officinalis (Ginger, Adhrak)}

It is from the family zingiberaceae and a very important medicinal plant. It contains $1-3 \%$ of volatile oil which provides it a unique flavor and fragrance. Ginger has activities of antimicrobials for numerous kind of bacteria, viruses, and fungi. In the root of ginger there is presence of antioxidant compounds which have the potential for anti-inflammation as well as boost the immune system. Thus ginger has special antiviral properties. Recent research has demonstrated that ginger could effectively alleviate nausea and emesis. The activation of vagal afferent mediated by serotonin (5-HT) is crucial in the mechanism of emesis. It was experimentally revealed that 6-shogaol, 6-gingerol and zingerone inhibited emetic signal transmission in vagal afferent neurons by suppressing the 5-HT receptor, and 6-shogaol had the strongest inhibitory efficacy. As Compared to dried ginger, fresh ginger is reported as it inhibit human respiratory syncytial virus (HRSV - it induces plaque formation) when taken in proper dose $(300 \mu \mathrm{g} / \mathrm{ml}$ - it reduces plaque count to $19.7 \%$ in case of A549 and 27\% in case of HEp-2) in both A549 (adenocarcinoma human alveolar) and HEp-2 ( human laryngeal carcinoma) cell lines.
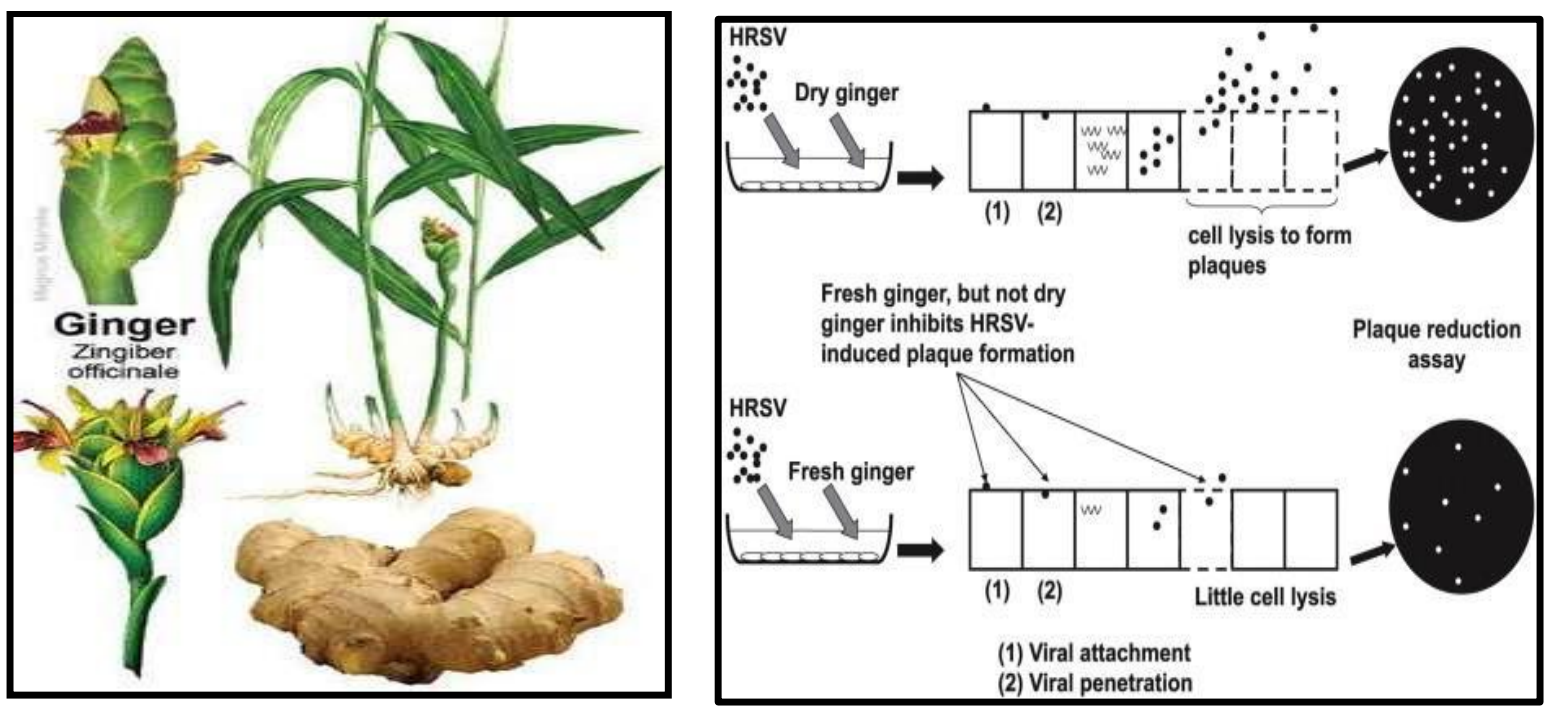

Fig.1. Zingiber officinalis and its mechanism of action

\subsection{Allium sativum (Garlic)}

Garlic the traditional curative plant product consists of sulfur based compounds, glucosides, amino acids, monoterpenoids, peptides, minerals, flavonoids and vitamins. Allium Sativum is mostly recommended for respiratory diseases (such as cold and cough) and Influenza virus. It has antiseptic, bacteriostatics, antiviral and anti-platelets effects which are used for the curing of chronic bronchitics, infections of respiratory tract which is helpful in boosting of the immune system and helpful to fight against virus and other deadly diseases. It enhances the immune system by stimulating WBC (NK and macrophages). Covid-19 infection spread with very fast track and the world was in need of medicine to cure patients. Patients of covid-19 infection were observed and it seems that there was decline in the number of T lymphocytes, the helper-cells (Cluster of Differentiation 4+) and the cytotoxics T-cells (CD8+). In severe cases the T-cells were much lower, and also there was reduction in IFN- $\gamma$. Garlic supplement, which significantly increases the number of CD4+ and CD8+ T-cells. It also stimulates NK cells. It decreases leptin, leptin-receptor, PPAR- $\gamma$ and IL-6 concentration. Allicin is the most biologically active component of garlic, it increases immune system function, stimulates macrophages, lymphocytes, NK-cells, DC and eosinophils. Garlic contains sulfur 


\title{
International Advanced Research Journal in Science, Engineering and Technology
}

\author{
Vol. 8, Issue 8, August 2021
}

\section{DOI: 10.17148/IARJSET.2021.8843}

containing phytochemicals like thiosulfinates (allicin) which is nearly $82 \%$, S-allyl cysteine sulfide, ajones, vinyldithiins and diallyl sulfide. In recent on relating by researchers it is found that the structure SARS- CoV has a serine type main protease whioch responsible for the replication of virus and for the production of functional protein via the use of in-Silico techniques. Garlic inhibits SARS-CoV-2, study of seven OSCs of alliin, S-(allyl/ methyl/ ethyl/ propyl)- cysteine, S-propyl L- cysteine, and S-allyl-mercapto-cysteine were the main constituents to inhibit Mpro of SARS-CoV-2 through hydrogen bond with this protease. Allicin has higher anti-viral potential to prevent covid -19 and is considered as the more efficient therapy with the lowest side effect and toxicity. The concentration of $0.1 \mathrm{ml}$ of garlic clove extract revealed potent in vivo inhibitory effects. The quercetin could also inhibit protease present in SARS-CoV during multiplication in host cells via blocking the viral attachment stage. Finally, the composition of functional foods prepared by encapsulated/ free bioactive compounds of garlic may have a role in the incidence reduction of covid-19.

\subsection{Tinospora cordifolia (Giloy, Guduchi)}

It is the herbal plant utilized as ayurvedic medication. It consists of phytochemicals such as lactones, alkaloids, steroids, diterpenoids, phenolics, sesquiterpenoids, glycosides, and aliphatic compounds. It has properties against diabetes, inflammation, periods, pasmodics, allergiies, wounds, osteoporotics, toxins, stress, cancer, HIV, cardio tonics, carminatives, having blood purifier property that improve digestive system. It is helpful in the detoxification of the body, improve eye disease, and treat type 2 diabetes, asthma, tumor, arthritis. Methanol, the extract of giloy that has antimicrobial properties and is very effective against various strains of bacteria such as S.Aureus, K. pneumoniae, E. coli, S. typhi, S. Typhimurium, S. Paratyphi, Shigella Flexneri and many more. Generally, the juice of giloy is taken because juice has broad beneficial effects to fight against infectious diseases and control cough, fever and support immunity. This plant also has essential phytochemicals and metabolites that enhances immunity which result in the improved defense system of the human body to deal against communicable disease like covid-19.

\subsection{Curcuma domestica (Turmeric, Haldi)}

It is a perennial herb. It consists of protein, fat, carbohydrates, minerals, dietary fibers, oils, and bioactive compounds curcuminoids. And the phytochemicals include diarylheptanoids such as bisdemethoxycurcumin, curcumina longa , demehoxycurcumine. The major groups for essential oils are germacrone, turmerone, zingiberene, atlantose. Turmeric is used for treating diseases like hemorrhage, jaundice, menstrual difficulties, and skin diseases. Mainly, the Rhizome part is used for the treatment and mostly consumed in raw forms. It is antiseptic because of antibacterial, antifungal, antiviral properties. Due to its antiviral properties it inhibits the replication of RNA virus, and is used in the treatment of respiratory tract infection, cold flu, cough, asthma, shortness of breathing and enhances the immune system. Curcumin decreases angiotensin-II receptor type-2 (AT1) which lowers the blood pressure and the mechanism is preventing angiotensin-II binding with AT1 which decreases binding of angiotensin-II with AT1, that result that unables the blood vessels to vonstrict, decreases perfusion of renal andtissues which is helpful in the lowering down of blood pressure. An investigation showed that the ACE inhibitor was unable to inhibit ACE2 enzyme. Preclinical studies shows that an RAAS inhibitor such as ACE inhibitor or ARB (angiotensin receptor blocker) might increase the expression level of Angiotensin Converting Enzyme 2. But another study of Renin Angiotensin Aldosterone System was against to the earlier study and it was concluded that RAAS inhibitor may or may not increases the ACE2 receptor. On seeing all these possibilities now the arises that is it safe on administration of curcumin to prevent covid-19, because ACE2 itself is also involved in hypertension mechanism. On other hand curcumin has anti-inflammatory properties and this anti-inflammatory effect of curcumin is because of presence of toll like receptor (TLR-4), phosphatidylinositol-3 kinase (P13K), nuclear factor-kappa B (NF-k $\beta$ ) and result in decrease production of IL-6, TNF$\alpha$, and IL-1 $\beta$ which are pro-inflammatory cytokines. Curcumin also has an immunostimulator effect as it increases InterLukin-6 and TNF $\alpha$ and this shows that curcumin can be used as immunomodulatory for immunostimulation and immunosuppressant. Therefore, all the evidence raises concern about the administration of curcumine as a treatment of coronavirus. But some patients show a hyper inflammatory and hypercytokinemia known as CRS or a cytokine storm that can be worse for coronavirus patients. Therefore, furthermore investigation is needed to clarify the effect of curcumin for covid-19. 


\section{International Advanced Research Journal in Science, Engineering and Technology}

Vol. 8, Issue 8, August 2021

DOI: $10.17148 /$ IARJSET.2021.8843

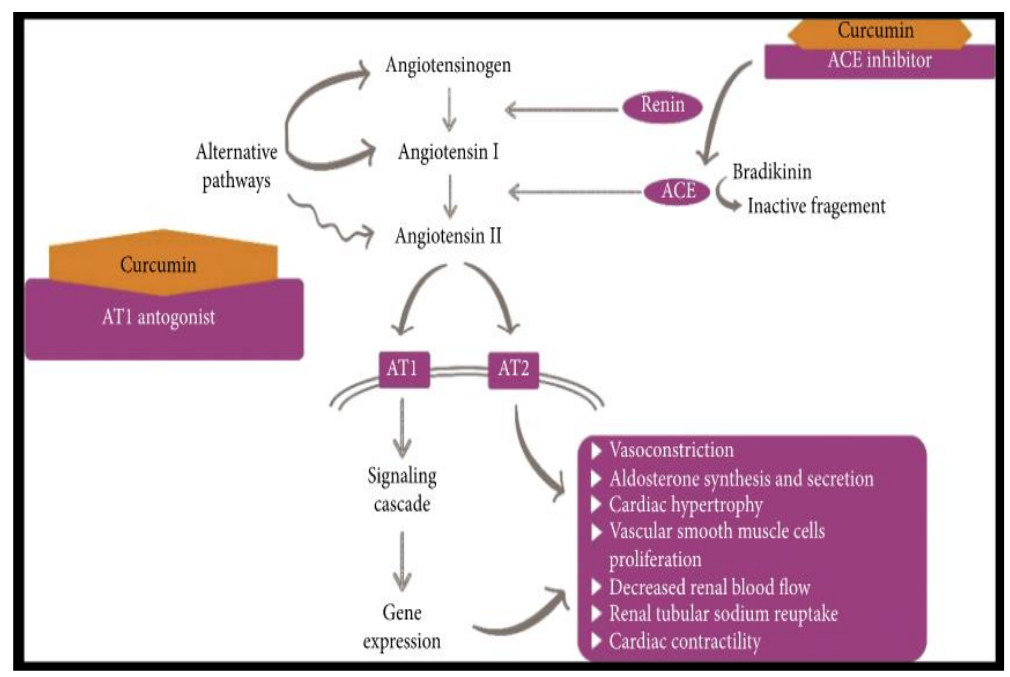

Fig.2. Mechanism of action of Curcuma domestica

\subsection{Withania somnifera (Ashwagandha)}

Ashwagandha used as a vitalizer. It is a phytochemical constituent of withanolides which is a source of Steroidal lactones, withaferin A and withaferin D the steroidal lactones are the derivatives of triterpene lactones-withanolides, alkaloids, cuscohygrine, tropine. All these constituents with anolides are bioactive compounds and have cyclooxygenase2 inhibition properties due to which they have anti-inflammatory and analgesic activities. The pharmacological activities of ashwagandha are mostly because of withaferin A and withanolide D. Ashwagandha root has antiviral properties. It is helpful in the inhibition of the binding of protein with the cells of host. According to researchers, it is reported that Ashwagandha is helpful in the reduction of the components of electrostatistics having binding free energies of ACE2-RBD enzyme complex and by blocking the entry of coronavirus. Generally, it causes ther blockage to the host protein interaction and helps to boosting up of the immune system to fight against the covid19 infection. It is also reported that the host cells ACE2 in the human body get entrapped by SARS-CoV2 by the help of its spike protein receptor binding domain (RBD). Basically, it blocks the host protein interaction and helps to boost the immunity against the covid-19 infection. Ashwagandha is helpful in the inhibition of SARS-CoV-2 diease into the cells of host by blocking and diminishing protein TMPRSS2 (Transmembrane protease, serine 2) of the host cell His296, Ser441 and Asp345 are the main Catalytic residues of TMPRSS2 which is involved in its proteolysis activity. Camostat mesylate, TIMPRESS2 inhibitor, seems to block the entry of SARS CoV2 virus into host cells. Camostat remains effective against different serine proteases. Due to its antiviral properties it is used as a reference molecule. Camostat mesylate get interacted with the TMPRSS2 and then compared with Ashwagandha withanolides, WithaferinA and Withanone and this complex show high docking score that are compatible with its potentialability for the blockage of TMPRSS2 the catalytic site. Ashwagandha is helpful in the inhibition of SARs-CoV-2 main protease enzyme (Mpro) which is most essential for the survival as Withanone has the capability to interact with SARS-CoV-2 main protease that is crucial for its formation of replicas and assembly inside the cells of host. Together, the predictions are made that Withanone posse's preventive and therapeutic potential for Covid-19.

\subsection{CIinchona officinalis (Cinchona, Quinine)}

The most preferable part is the bark of the cinchona tree. Alkaloids are present in the bark in a high amount, the chemical quinine, which has excellent anti-malarial properties along with it is anti-parasitic, antispasmodic, antiprotozoa, cardio tonic, anti-arrhythmic. Chloroquine is used earlier against HIV and then used against SARS novel coronavirus 1and SARS CoV-2. Chloroquine has a property that it can raise the potency of Hydrogen of lysosomes in the host and thus interfere with the virus strategy for the acidification of the lysosomes, which is highly needed for the building of autophagosomes where cell eat themselves via phagocytosis and pincocytosis. 
DOI: $10.17148 /$ IARJSET.2021.8843

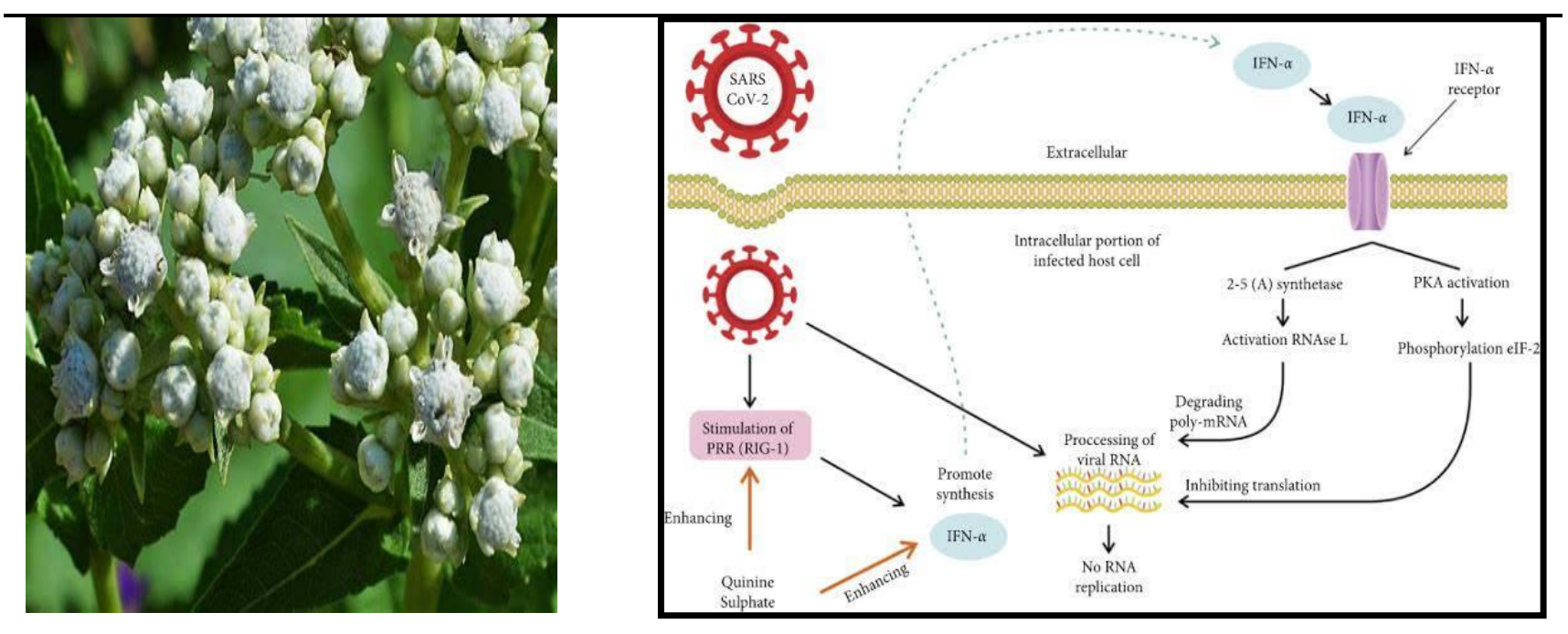

Fig.3. Clinchona officinalis and its mechanism of action

\subsection{Nigella sativa (Black cumin, Kalonji)}

With broad therapeutic value we can cure various human health diseases like conjunctivitis, diabetes, anorexia, asthma, cough, jaundice, fever, diabetes, bronchitis, conjunctivitis, gastrointestinal problems, anorexia, intrinsic haemorrhage, rheumatism, etc. The main active phytochemical present in black cumin is Thymoquinone which is mostly in consideration for its therapeutic properties. Due to properties of antivirulence it cures deadly viral diseases like hepatitis $\mathrm{C}$ and Human Immuno Virus. Black cumin enhances the number of Cluster of Differentiation $4^{+} \mathrm{T}$ lymphocytes and macrophages which are present in serum and increases production of interferons. It was studied that Nigella contains some significant compounds that include Dithymoquinone (major bioactive component), Tannin and Rutin. All these compounds showed significant interaction and inhibitory potential and a strong affinity with several residues of receptor-binding domain RdRp and helicase of SARS-CoV-2. And it was also shown that Nigella sativa has strong binding affinity against protease and spike protein. Some other studies show the significant inhibitory potential of Nigella Sativa compounds such as isothymol, heherdagenin and some tannins which are helpful against the binding domains of receptors and protease SARS-CoV-2 viral disease. Due to its evidence - healing power it is considered one of the top ranked herbal medicines and thus can be further explored to combat the covid-19 to enhance the immune system and also for general well-being.

\subsection{Azadirachta indica (Margosa Neem)}

No part of neem is left which cannot be used to cure diseases that arosen from parasite, bacteria, virus, fungi or any other causes. Neem is commonly found in India and is called "Free tree of India" Nimba is another name for it which means 'Giver of good health'. It is also called '40 Cures'. The phyto chemicals of neem are limonoide and terpenes having anti-malarial, anti-bacterial, anti-inflammatory, anti-fungal, anti-cancerous, immunomodulatory and hepatoprotective effects; wound healing effects, anti-diabetic activities and so on. Its chemical composition includes neem nimbidin, Gallic acid, catechin, sodium nimbidate. Small amount of leaves are taken orally for the killing of microbes inside the body thart are treated as harmfdul. It is helpful in the regulation of blood sugar levels. Neem leaves are known to have $100+$ compounds and on which $20+$ compounds show high inhibiting power against novel coronavirus main proteases 6LU7 structurewith value ranging from $-14.3 \mathrm{Kcal} / \mathrm{Mol}$ to a minimum of $-9.1 \mathrm{Kcal} / \mathrm{Mol}$ and some compounds of neem leaves exhibits medium binding affinities with Covid-19 main protease. Compounds such as Meliacinanhydride, Nimocinol, Isomeldenin, Zafaral, Nimbandiol, Nimbin, Nimbinene and Desacetyl Nimbin are selected for the study. Nimbin the isolate of neem is a kind of a triterpenoid, high in oil quantity alongwith activities against inflammations, fungi, histamines, pyretic as well as antiseptic properties have a binding affinity for the spike 


\section{International Advanced Research Journal in Science, Engineering and Technology}

Vol. 8, Issue 8, August 2021

\section{DOI: $10.17148 / I A R J S E T .2021 .8843$}

glycoproteins and the ACE-2 enzyme receptor of SARS-CoV-2. They are having good pharmacokinetic properties. As covid-19 is responsible for severe cytokine storm induced complications and coagulopathies. Neem inhibits proinflammatory cytokines and also it shows thrombolytic properties and immunomodulator activities due to which it is known as 'single silver bullet'. Neem has a possible role as prophylactic medicine and curative medicine to avoid long term effects on lungs in post covid cases. It helps in the healing of alveolar cells in post covid cases.

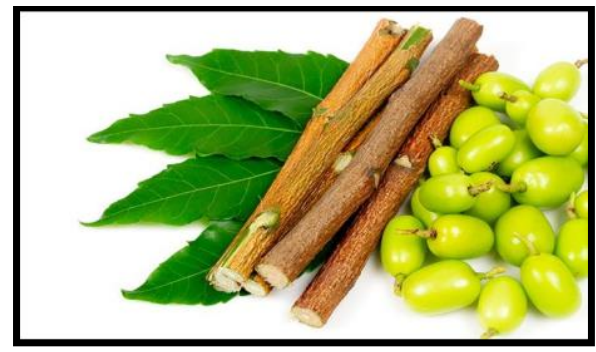

Fig. 4. Azadirachta indica

\subsection{Glycyrrhiza glabra (Licorice)}

This herb is high in properties against diabetes, inflammations, fungi, tumor, ulcer, diuretic diseases as well as act as antioxidants. The shoot of this herb can be used for many medicinal puposes as well as to cure asthma, cold and pulmonary disease. It has potential phytochemical agent against COVID-19. it is reported about the binding of ACE2, as well as down-regulating cytokines that are preo inflammatory and blocks the inhibiting process of accumulation of intracellulic Reactive Oxygen Species, thrombins, hyper production of airways exudation and induction of endogenous interferons. This herb is effective against SARS-CoV as it was tested that 15 derivatives of glycyrrhizin are identified SARS-CoV antivirulence properties and it has been reported that they are helpful in the depiction of upto 70 folds increased activity against COVID disease via the help of theie 15 glycyrrhizin derivatives having groups of amides and conjugates of amides with 3Ofreecarboxylic acid $\mathrm{COOH}$ groups. It also contains some biologically active compounds including flavonoids i.e., glabridin, glycoumarin and liquirtigenin having numerous kind of phytonutrirnts, glycyrrhizin - a compound which looks like saponin, glycyrrhetinic acid or Enoxolone, isoflavonoids also known by the name of phytoestrogens, terterpenoids or isoprenoids and chalcones the polyphenolic compounds. All these biological compounds significantly interacted and stabilized the affinity with Mpro of SARS-CoV-2 Virus

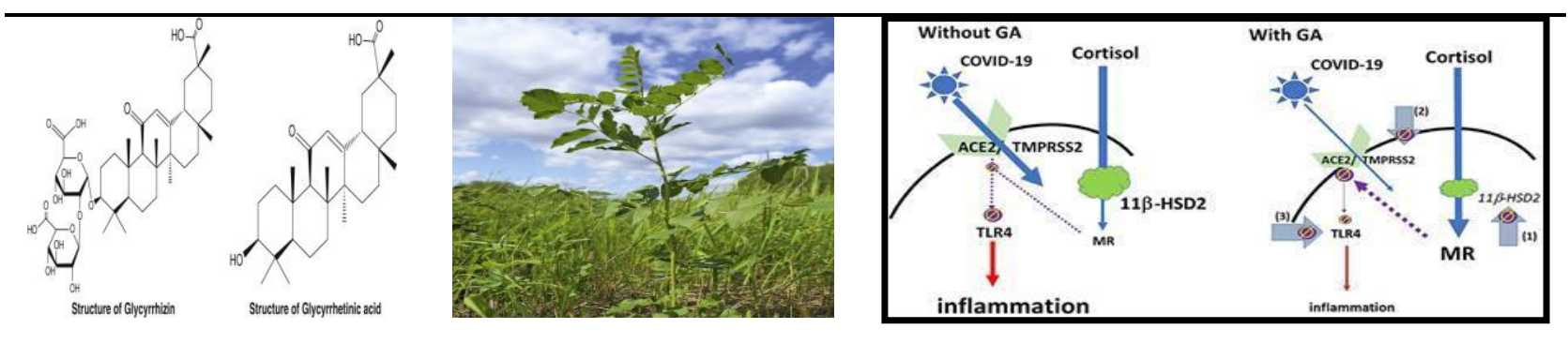

Fig.5. Glycyrrhiza glabra and its mechanism of action

\section{CONCLUSION}

Herbal medicines have the ability to interfere with the activity of virus by acting as immunity boosters. These herbal medicines have the capabilities to regulate the production and release of proinflammatory cytokines which interfers in the the development of virus host cells by modifying the molecular pathways. The administration of the herbal botanicals must be applied after few rounds of clinical trials so it is suggested to consume them after consulting with the doctor as they also have the possibility in induction of several harmful effects depending upon the immune system tolerance. Consumption of foods which have antiviral and immunomodulatory properties are also recommended alongwith balanced diet. 


\title{
International Advanced Research Journal in Science, Engineering and Technology
}

\author{
Vol. 8, Issue 8, August 2021
}

\section{DOI: 10.17148/IARJSET.2021.8843}

\section{REFERENCES}

1. Lipsitch, M., Swerdlow, D. L., \& Finelli, L. (2020). Defining the epidemiology of Covid-19—studies needed. New England journal of medicine, 382(13), 1194-1196

2. R. V., Ridwansyah, H., Ghozali, M., Khairani, A. F., \& Atik, N. (2020). Traditional herbal medicine candidates as complementary treatments for COVID-19: a review of their mechanisms, pros and cons. Evidence-Based Complementary and Alternative Medicine, 2020.

3. Adhikari, S. P., Meng, S., Wu, Y. J., Mao, Y. P., Ye, R. X., Wang, Q. Z., ... \& Zhou, H. (2020). Epidemiology, causes, clinical manifestation and diagnosis, prevention and control of coronavirus disease (COVID-19) during the early outbreak period: a scoping review. Infectious diseases of poverty, 9(1), 1-12.

4. Huang, C., Wang, Y., Li, X., Ren, L., Zhao, J., Hu, Y., ... \& Cao, B. (2020). Clinical features of patients infected with 2019 novel coronavirus in Wuhan, China. The lancet, 395(10223), 497-506.

5. Zhang, L., \& Liu, Y. (2020). Potential interventions for novel coronavirus in China: A systematic review. Journal of medical virology, 92(5), 479-490.

6. Sharma, M., Anderson, S. A., Schoop, R., \& Hudson, J. B. (2009). Induction of multiple pro-inflammatory cytokines by respiratory viruses and reversal by standardized Echinacea, a potent antiviral herbal extract. Antiviral research, 83(2), 165-170.

7. Kocaadam, B., \& Sanlier, N. (2017). Curcumin, an active component of turmeric (Curcuma longa), and its effects on health. Critical reviews in food science and nutrition, 57(13), 2889-2895.

8. Zu, Z. Y., Jiang, M. D., Xu, P. P., Chen, W., Ni, Q. Q., Lu, G. M., \& Zhang, L. J. (2020). Coronavirus disease 2019 (COVID-19): a perspective from China. Radiology, 296(2), E15-E25.

9. Deng, S. Q., \& Peng, H. J. (2020). Characteristics of and public health responses to the coronavirus disease 2019 outbreak in China. Journal of clinical medicine, $9(2), 575$.

10. Fehr, A. R., \& Perlman, S. (2015). Coronaviruses: an overview of their replication and pathogenesis. Coronaviruses, 1-23.

11. Jiang, X., Rayner, S., \& Luo, M. H. (2020). Does SARS-CoV-2 has a longer incubation period than SARS and MERS?. Journal of medical virology, 92(5), 476-478.

12. Prompetchara, E., Ketloy, C., \& Palaga, T. (2020). Immune responses in COVID-19 and potential vaccines: Lessons learned from SARS and MERS epidemic. Asian Pacific journal of allergy and immunology, 38(1), 1-9.

13. Chen, Y., \& Li, L. (2020). SARS-CoV-2: virus dynamics and host response. The Lancet Infectious Diseases, 20(5), 515-516.

14. Liu, Q., Zhou, Y. H., \& Yang, Z. Q. (2016). The cytokine storm of severe influenza and development of immunomodulatory therapy. Cellular \& molecular immunology, 13(1), 3-10.

15. Mehta, P., McAuley, D. F., Brown, M., Sanchez, E., Tattersall, R. S., \& Manson, J. J. (2020). COVID-19: consider cytokine storm syndromes and immunosuppression. The lancet, 395(10229), 1033-1034.

16. Drosten, C., Günther, S., Preiser, W., Van Der Werf, S., Brodt, H. R., Becker, S., ... \& Doerr, H. W. (2003). Identification of a novel coronavirus in patients with severe acute respiratory syndrome. New England journal of medicine, 348(20), 1967-1976.

17. Zaki, A. M., Van Boheemen, S., Bestebroer, T. M., Osterhaus, A. D., \& Fouchier, R. A. (2012). Isolation of a novel coronavirus from a man with pneumonia in Saudi Arabia. New England Journal of Medicine, 367(19), 1814-1820.

18. Huang, C., Wang, Y., Li, X., Ren, L., Zhao, J., Hu, Y., ... \& Cao, B. (2020). Clinical features of patients infected with 2019 novel coronavirus in Wuhan, China. The lancet, 395(10223), 497-506.

19. Singgih Wahono, C., Diah Setyorini, C., Kalim, H., Nurdiana, N., \& Handono, K. (2017). Effect of curcuma xanthorrhiza supplementation on systemic lupus erythematosus patients with hypovitamin d which were given Vitamin D3 towards Disease Activity (SLEDAI), IL-6, and TGF- $\beta 1$ serum. International journal of rheumatology, 2017.

20. Liles, N. W., Page, E. E., Liles, A. L., Vesely, S. K., Raskob, G. E., \& George, J. N. (2016). Diversity and severity of adverse reactions to quinine: a systematic review. American journal of hematology, 91(5), 461-466.

21. World Health Organization. (2020). COVID-19: operational guidance for maintaining essential health services during an outbreak: interim guidance, 25 March 2020 (No. WHO/2019-nCoV/essential_health_services/2020.1). World Health Organization. 22. Wang, W., Xu, Y., Gao, R., Lu, R., Han, K., Wu, G., \& Tan, W. (2020). Detection of SARS-CoV-2 in different types of clinical specimens. Jama, 323(18), 1843-1844.

22. Dhama, K., Khan, S., Tiwari, R., Sircar, S., Bhat, S., Malik, Y. S., ... \& Rodriguez-Morales, A. J. (2020). Coronavirus disease 2019COVID-19. Clinical microbiology reviews, 33(4), e00028-20.

23. Wang, M., Cao, R., Zhang, L., Yang, X., Liu, J., Xu, M., ... \& Xiao, G. (2020). Remdesivir and chloroquine effectively inhibit the recently emerged novel coronavirus (2019-nCoV) in vitro. Cell research, 30(3), 269-271.

24. Wang, M., Cao, R., Zhang, L., Yang, X., Liu, J., Xu, M., ... \& Xiao, G. (2020). Remdesivir and chloroquine effectively inhibit the recently emerged novel coronavirus (2019-nCoV) in vitro. Cell research, 30(3), 269-271.

25. Hudson, J., \& Vimalanathan, S. (2011). Echinacea-A source of potent antivirals for respiratory virus infections. Pharmaceuticals, 4(7), $1019-1031$.

26. Burger, R. A., Torres, A. R., Warren, R. P., Caldwell, V. D., \& Hughes, B. G. (1997). Echinacea-induced cytokine production by human macrophages. International journal of immunopharmacology, 19(7), 371-379.

27. Kumar, V., Abbas, A. K., Fausto, N., \& Aster, J. C. (2014). Robbins and Cotran pathologic basis of disease, professional edition e-book. Elsevier health sciences.

28. Hadi, A., Pourmasoumi, M., Ghaedi, E., \& Sahebkar, A. (2019). The effect of Curcumin/Turmeric on blood pressure modulation: A systematic review and meta-analysis. Pharmacological research, 150, 104505.

29. Lekshmi, P. C., Arimboor, R., Nisha, V. M., Menon, A. N., \& Raghu, K. G. (2014). In vitro antidiabetic and inhibitory potential of turmeric (Curcuma longa L) rhizome against cellular and LDL oxidation and angiotensin converting enzyme. Journal of food science and technology, 51(12), 3910-3917.

30. Pooja Dahiya; Roopsi Kaushik; Anil Sindhu. "Physiological Analysis of Dairy Effluent". International Research Journal on Advanced Science Hub, 2, Special Issue ICAET 11S, 2020, 20-29. doi: 10.47392/irjash.2020.228

31. Pooja Dahiya; Roopsi Kaushik; Anil Sindhu. "An Introduction to Plant Growth Promoting Rhizobacteria, Antifungal Metabolites Biosynthesis using PRPR with reference to Pseudomonas species and It's other characteristics like Antagonistic and Biocontrolling properties". International Research Journal on Advanced Science Hub, 2, Special Issue ICAMET 10S, 2020, 95-100. doi: 10.47392/irjash.2020.205 32. Leong, X. F. (2018). The spice for hypertension: protective role of Curcuma longa. Biomedical and Pharmacology Journal, 11(4), 18291840. 


\section{International Advanced Research Journal in Science, Engineering and Technology}

Vol. 8, Issue 8, August 2021

\section{DOI: $10.17148 / I A R J S E T .2021 .8843$}

33. Akinyemi, A. J., Adedara, I. A., Thome, G. R., Morsch, V. M., Rovani, M. T., Mujica, L. K. S., ... \& Schetinger, M. R. C. (2015). Dietary supplementation of ginger and turmeric improves reproductive function in hypertensive male rats. Toxicology reports, 2, 1357-1366.

34. Yao, Y., Wang, W., Li, M., Ren, H., Chen, C., Wang, J., ... \& Zeng, C. (2016). Curcumin exerts its anti-hypertensive effect by downregulating the AT 1 receptor in vascular smooth muscle cells. Scientific reports, 6(1), 1-8.

35. Sadler, A. J., \& Williams, B. R. (2008). Interferon-inducible antiviral effectors. Nature reviews immunology, 8(7), 559-568.

36. Remya S. "Covid19 and Environment-A Theoretical Review from Higher Education Students Perspective". International Research Journal on Advanced Science Hub, 2, Special Issue ICARD 2020, 2020, 227-230. doi: 10.47392/irjash.2020.124

37. Maldonado, C., Barnes, C. J., Cornett, C., Holmfred, E., Hansen, S. H., Persson, C., ... \& Rønsted, N. (2017). Phylogeny predicts the quantity of antimalarial alkaloids within the iconic yellow Cinchona bark (Rubiaceae: Cinchona calisaya). Frontiers in Plant Science, $8,391$.

38. Vaduganathan, M., Vardeny, O., Michel, T., McMurray, J. J., Pfeffer, M. A., \& Solomon, S. D. (2020). Renin-angiotensin-aldosterone system inhibitors in patients with Covid-19. New England Journal of Medicine, 382(17), 1653-1659.

39. Abolghasemi, E., Moosa-Kazemi, S. H., Davoudi, M., Reisi, A., \& Satvat, M. T. (2012). Comparative study of chloroquine and quinine on malaria rodents and their effects on the mouse testis. Asian Pacific journal of tropical biomedicine, 2(4), 311-314.

40. Catanzaro, M., Corsini, E., Rosini, M., Racchi, M., \& Lanni, C. (2018). Immunomodulators inspired by nature: a review on curcumin and echinacea. Molecules, 23(11), 2778 .

41. Shimizu, K., Funamoto, M., Sunagawa, Y., Shimizu, S., Katanasaka, Y., Miyazaki, Y., ... \& Morimoto, T. (2019). Anti-inflammatory action of curcumin and its use in the treatment of lifestyle-related diseases. European Cardiology Review, 14(2), 117.

42. Malakar, S., Sreelatha, L., Dechtawewat, T., Noisakran, S., Yenchitsomanus, P. T., Chu, J. J. H., \& Limjindaporn, T. (2018). Drug repurposing of quinine as antiviral against dengue virus infection. Virus research, 255, 171-178.

43. Vincent, M. J., Bergeron, E., Benjannet, S., Erickson, B. R., Rollin, P. E., Ksiazek, T. G., ... \& Nichol, S. T. (2005). Chloroquine is a potent inhibitor of SARS coronavirus infection and spread. Virology journal, 2(1), 1-10.

44. Seeler, A. O., Graessle, O., \& Ott, W. H. (1946). Effect of quinine on influenza virus infections in mice. The Journal of infectious diseases, 156-158. 